\title{
FORMAÇÃO CONTINUADA: INDICAÇÕES PARA O ENSINO À DISTÂNCIA DAS CIÊNCIAS BIOLÓGICAS NO ENSINO FUNDAMENTAL E MÉDIO
}

\section{ARTIGO ORIGINAL}

DENDASCK, Carla Viana ${ }^{1}$, OLIVEIRA, Euzébio de ${ }^{2}$, FECURY, Amanda Alves ${ }^{3}$, DIAS, Claudio Alberto Gellis de Mattos ${ }^{4}$

DENDASCK, Carla Viana. Et al. Formação continuada: indicações para o ensino à distância das ciências biológicas no ensino fundamental e médio. Revista Científica Multidisciplinar Núcleo do Conhecimento. Ano 06, Ed. 08, Vol. 06, pp. 171186. Agosto de 2021. ISSN: 2448-0959, Link de acesso: https://www.nucleodoconhecimento.com.br/educacao/ciencias-biologicas, $\quad$ DOI: 10.32749/nucleodoconhecimento.com.br/educacao/ciencias-biologicas

\section{RESUMO}

Embora as discussões sobre a possibilidade de educação online no ensino fundamental e médio no Brasil tenham entrado na esteira do debate teórico, ainda se encontra uma grande resistência. No entanto, o contexto pandêmico não trouxe alternativas, levando milhares de alunos ao isolamento social por mais de um ano. Este contexto fez com que professores do ensino fundamental e médio tivessem que

\footnotetext{
${ }^{1}$ Teóloga, Doutora em Psicanálise Clínica. Atua há 15 anos com Metodologia Científica ( Método de Pesquisa) na Orientação de Produção Científica de Mestrandos e Doutorandos. Especialista em Pesquisas de Mercado e Pesquisas voltadas à área da Saúde. Doutoranda em Comunicação e Semiótica (PUC SP).

2 Biólogo, Doutor em Doenças Tropicais, Professor e pesquisador do Curso de Educação Física, Universidade Federal do Pará (UFPA).

${ }^{3}$ Biomédica, Doutora em Doenças Tropicais, Professora e pesquisadora do Curso de Medicina do Campus Macapá, Universidade Federal do Amapá (UNIFAP), Pró-reitora de Pesquisa e Pós-Graduação (PROPESPG) da Universidade Federal do Amapá (UNIFAP).

${ }^{4}$ Biólogo, Doutor em Teoria e Pesquisa do Comportamento, Professor e pesquisador do Curso de Licenciatura em Química do Instituto de Ensino Básico, Técnico e Tecnológico do Amapá (IFAP) e do Programa de Pós Graduação em Educação Profissional e Tecnológica (PROFEPT IFAP).
}

RC: 96069

Disponível em: https://www.nucleodoconhecimento.com.br/educacao/ciencias- 
se adaptar às novas tecnologias, demonstrando então a necessidade de se preparar para atuar no ensino de aprendizagem remoto. A pergunta norteadora desse material foi: Como os professores de ciências biológicas podem se preparar e quais ferramentas básicas devem conhecer para preparar suas aulas online? Assim, o objetivo geral foi realizar indicações que os professores devem conhecer para preparar suas aulas online. A metodologia adotada foi a exploratória através de revisão de literatura. As principais indicações foram que os professores precisam buscar conteúdos diversificados na preparação de aulas para adotar estratégias de motivação junto aos seus alunos, adotando cuidados com a questão da linguagem, áudio e luz na produção das aulas. Por fim, caberá ao professor reconhecer as diversas ferramentas e recursos como: Youtube, Instagram, Filmes, Jogos, e demais subsídios, a fim de que haja uma aproximação entre o ensino da biologia e a realidade do aluno.

Palavras-chave: Formação Docente, Educação à distância, Ensino de Biologia.

\section{INTRODUÇÃO}

Desde o final de 2019 o mundo se deparou frente ao vírus SARS/COVID-19. Sua alta capacidade contágio, acometimento de órgãos vitais, especialmente os pulmões, e o desconhecimento da comunidade científica, levaram os Organismos Internacionais a decretarem situação global pandêmica, indicando afastamento social imediato. Tal medida impactou diretamente as organizações que tiveram de se adaptar às novas realidades, usando, como nunca antes, os meios tecnológicos para viabilizar a continuidade de suas respectivas funcionalidades. De acordo com Gonçalves et al. (2020), no Brasil, uma das instituições mais prejudicadas foram as escolas, especialmente as escolas públicas, pois, além de enfrentarem problemas com relação a acessibilidade de ferramentas tecnológicas, seus professores não estavam preparados para esta realidade, e muitos resistiam à ideia do ensino online, especialmente no ensino médio e fundamental.

RC: 96069

Disponível em: https://www.nucleodoconhecimento.com.br/educacao/ciencias- 
Lenzi e Santos (2021) aludiram que mesmo com as vacinas e retorno às aulas presenciais, é importante que os professores se adaptem às rotinas do ensino à distância, especialmente no que se tem defendido pelos professores como: ensino híbrido, pois esse contexto já é uma realidade. Desta feita, a justificativa deste estudo está em fornecer alguns subsídios indicativos que os professores devem considerar ao preparar suas aulas online, partindo da seguinte questão norteadora: Como os professores de ciências biológicas podem se preparar e quais as ferramentas básicas devem conhecer para preparar suas aulas online? Desta forma, o objetivo geral deste estudo será: realizar indicações que os professores devem conhecer para preparar suas aulas online.

Como objetivos específicos serão considerados: a) Demonstrar as principais dificuldades do ensino online das ciências biológicas e a importância da utilização das tecnologias; b) Buscar ferramentas que possam ser incorporadas no ensino online; c) Fornecer indicativos e instruções tecnológicas que devem ser consideradas pelo professor de biologia. Desta forma, na fundamentação teórica, recorreu-se a uma pesquisa ampla no Google Academic, utilizando como descritores: "Ferramentas para o ensino online de Biologia"; "Ensino EAD da Biologia"; "Ensino Híbrido das Ciências Biológicas"; "Ensino Híbrido da Biologia". Como critério de inclusão foi considerado materiais que pudessem contribuir com o problema e objetivos aqui expostos. Foram selecionados 20 materiais, dentre eles, artigos científicos, livros e manuais. Em posse desses, nos resultados e discussões foi realizado uma tabela com indicações de ferramentas básicas e considerações gerais para serem adotadas no ensino da biologia online.

\section{A IMPORTÂNCIA DA EDUCAÇÃO CONTINUADA DE PROFESSORES}

A história da humanidade é direcionada e constituída a partir de diferentes perspectivas sociais, políticas, científicas e econômicas, sendo que todas essas

RC: 96069

Disponível em: https://www.nucleodoconhecimento.com.br/educacao/ciencias- 
dimensões são afetadas pelo avanço tecnológico (TREBIEN et al., 2020). Toda mudança social e do sistema afeta diretamente o processo educacional na escola, e, desse modo, a instituição escolar deve acompanhar tais avanços (RODRIGUES; LIMA; VIANA, 2017). A escola deve se adaptar ao novo modelo. Diante desse cenário, o docente encontra-se fortemente envolvido em um processo que implica constantes mudanças a fim de que possa atender os desafios impostos pela sociedade. Isso ocorre porque vive-se na era da informação e, assim, a formação inicial do docente já não é mais um requisito suficiente à garantia do domínio do conteúdo e da qualidade pedagógica (JUNGES; KETZER; OLIVEIRA, 2018).

A formação continuada admite as atividades desenvolvidas pelos docentes após a primeira formação. Esta se dá quando o profissional ingressa no magistério. Ela pode ser individual ou coletiva (TREBIEN et al., 2020). Torna-se indispensável, portanto, um processo de formação que seja permanente e contínuo, enraizado em uma epistemologia da prática e do cotidiano, sendo capaz de subsidiar uma ação educativa inovadora e consciente (JUNGES; KETZER; OLIVEIRA, 2018). Em razão da relevância da continuidade da formação do professor, a Lei de Diretrizes e Bases da Educação (LDB), contém um capítulo que enfatiza o assunto e fornece subsídios para esta formação: "[...] a associação entre teorias e práticas, inclusive mediante a capacitação em serviço", na sequência no parágrafo único, destaca à "formação continuada para os profissionais, no seu local de trabalho" (TREBIEN et al., 2020, p. 94).

Diante do aumento e do aperfeiçoamento de políticas voltadas à formação continuada, sobretudo em razão da preocupação com a qualidade do exercício docente, a temática tem suscitado novas ações. Torna-se, então, necessária a adesão a um programa de formação continuada bem elaborado e com finalidades bem estruturadas, compreendendo não apenas as necessidades do professor, mas sim de todo o sistema de ensino, envolvendo os professores nesse processo de planejamento, que deve ser participativo, colaborativo e deve admitir as suas reais

RC: 96069

Disponível em: https://www.nucleodoconhecimento.com.br/educacao/ciencias- 
necessidades (RODRIGUES; LIMA; VIANA, 2017). Para que os seus saberes e a sua práxis sejam valorizados, o docente, junto aos seus pares, deve refletir e dialogar, ajudando os demais a superarem seus conflitos (FALSARELLA, 2004). Desta forma, a formação continuada contribuirá com o desenvolvimento da autonomia do professor e dinamicidade de sua prática diária:

[...] a formação continuada como proposta intencional e planejada, que visa à mudança do educador através de um processo reflexivo, crítico e criativo, conclui-se que deva motivar o professor a ser ativo agente na pesquisa de sua própria prática pedagógica, produzindo conhecimento e intervindo na realidade (FALSARELLA, 2004, p. 50).

A formação continuada do professor implica na adesão de uma postura contínua que implica a reflexão, pesquisa, ação, descoberta, organização, fundamentação, revisão e construção teórica. Não implica apenas o aprendizado de novas técnicas pedagógicas ou das últimas inovações pedagógicas (FALSARELLA, 2004). Nesse sentido, o processo de formação permanente deve estar pautado na realidade de cada escola, sendo necessário que os encontros pedagógicos e demais momentos de formação, dentro e fora da escola, repensados a cada dia, de forma a acompanhar as mudanças da própria sociedade (GADOTTI, 2008). O papel do professor nesse contexto altamente mutável e dinâmico, implica a contextualização dos conteúdos ensinados, a fim de que a aprendizagem se torne significativa, o que demanda um exercício constante de reflexão crítica.

[...] os saberes teóricos propositivos se articulam, pois, aos saberes da prática, ao mesmo tempo ressignificando-se e sendo por eles ressignificados. O papel da teoria é oferecer aos professores perspectivas de análises para compreender os contextos históricos, sociais, culturais, organizacionais, e de si mesmos como profissionais, nos quais se dá sua atividade docente, para neles intervir, transformando-os (GHEDIN, 2012, p. 31).

É necessário que o docente se aproprie da teoria a fim de que possa refletir e interpretar a prática docente em consonância com as demandas da sociedade, o que implica em mudanças no fazer pedagógico, para que seja possível fortalecer a autonomia e a dinamicidade do professor (TREBIEN et al, 2020). A prática

RC: 96069

Disponível em: https://www.nucleodoconhecimento.com.br/educacao/ciencias- 
pedagógica é o ponto de partida e chegada do processo de formação continuada e, ao mesmo tempo, é um caminho que possibilita a transformação da ação do professor, e, dessa forma, busca-se na fundamentação teórica de subsídios que permitem o fortalecimento da práxis de forma reflexiva, dialógica e interativa (GHEDIN, 2012). Cabe ao professor, portanto, estar disposto a inovar, para que consiga atender às demandas da sociedade no âmbito do ensino, para que, assim, consiga transformar a prática e a atuação profissional (RODRIGUES; LIMA; VIANA, 2017).

A partir do momento em que se passa a refletir sobre a formação continuada e como esta deve se adaptar frente aos múltiplos avanços (incluindo aqueles de ordem tecnológica), exige-se uma consciência intencionada à qualidade social da educação e do fazer pedagógico escolar (JUNGES; KETZER; OLIVEIRA, 2018). Assim sendo, entende-se que uma educação de qualidade epistemológica e social advoga em prol de um objetivo fundamental: defende-se a necessidade de uma prática pedagógica criativa e estratégia, e, dessa forma, ela não deve ser moldada pela simples repetição de práticas já existentes (GHEDIN, 2012). Nesse sentido, torna-se essencial a elaboração e aplicação de políticas voltadas à formação. Hoje em dia, aquelas voltadas à atuação das tecnologias em sala de aula é fundamental. É uma realidade que exige cuidado com o manuseio da teoria e da prática no exercício docente (TREBIEN et al, 2020).

Entretanto, há que se chamar a atenção para um problema enfrentado pelo sistema brasileiro de ensino. No Brasil, historicamente, os modelos predominantes de formação continuada têm privilegiado uma concepção meramente instrumental do trabalho docente (FERREIRA; ALBUQUERQUE; LEAL, 2007). Nesse sentido, o professor é levado a reproduzir técnicas e, de forma passiva, executa as propostas que já chegam prontas. Percebe-se que, em muitas vezes, as normativas prescrevem um modelo de ensino que direciona o aluno a uma aprendizagem ativa, participativa e autônoma. Todavia, na prática, não há uma articulação desse saber

RC: 96069

Disponível em: https://www.nucleodoconhecimento.com.br/educacao/ciencias- 
pedagógico nos cursos de formação continuada (TREBIEN et al., 2020). Contudo, a formação continuada contribui com 0 aprimoramento do professor $e$, consequentemente, da qualidade do ensino. Assim, diversos saberes da prática educativa tornam-se necessários à ressignificação da prática docente, o que implica uma busca e aprendizado constante por parte do professor.

\section{ENSINO A DISTÂNCIA COMO FERRAMENTA PARA EDUCAÇÃO CONTINUADA}

O uso das tecnologias e o ensino à distância é uma realidade que precisa ser incorporada pelos professores, já que a pandemia causou uma espécie de ruptura das relações, e, consequentemente, na educação. Estima-se que mesmo com o controle do COVID, a escola deverá se adaptar a uma outra realidade, se não ensino totalmente online, pelo menos a adoção por modelos híbridos (LENZI et al., 2021). Com relação às dificuldades do ensino online, Gonçalves et al. (2020) consideraram a relação entre a escola e a família fundamentais, pois caberá a esta, acompanhar o desenvolvimento do aluno em sua casa. Nicola e Paniz (2016) aduzem que independente da tecnologia escolhida, é importante que o professor tenha em mente que a diversificação dos recursos tecnológicos didáticos será essencial para o sucesso do ensino aprendizagem.

Além disso, é necessário buscar ambientes que traduzam a realidade cotidiana e a necessidade da sociedade que o aluno está inserido (ARAÚJO et al. 2011).

[..] a "sala de aula", traduzida em um espaço virtual onde as lições são disponibilizadas, não é suficiente para garantir o resultado pretendido. Tal como em uma escola, nos moldes mais tradicionais, há que se considerar todos os agentes envolvidos. Cumpre ainda assim dizer que mesmo que se tenha uma noção mais próxima da realidade e que se tenha o ideal dos participantes do processo, isso não é suficiente para afiançar 0 atingimento dos objetivos educacionais propostos. Em outras palavras, não se trata de ter os componentes de uma escola e juntá-los no mesmo local. O que se quer com o conceito de escola é a integração harmônica das peças

RC: 96069

Disponível em: https://www.nucleodoconhecimento.com.br/educacao/ciencias- 
para que o funcionamento dessa engrenagem apresente o mínimo possível de arestas (SOARES FILHO, 2013, p.418).

Olivetti e Periotto (2014), ao entrevistar 88 professores, concluíram que a capacitação continuada é fundamental para que a efetividade do uso de tecnologias dentro do ensino da biologia, pois, a biologia, por si só sempre necessitou de outros recursos além dos teóricos, como por exemplo: laboratórios e campo. Além disso, o professor deve ter em mente que o ensino da biologia se trata de uma ferramenta para construção crítica e social do sujeito, e, portanto, deve-se utilizar de todos os recursos para que o aluno tenha um melhor desempenho (LEITE et al., 2017), inclusive com a adoção da consciência de que o aluno deve entender a biologia dentro de sua realidade do cotidiano (DURÉ et al., 2018).

Repensando, então, o ensino da biologia, Brandim e Nogueira (2018); Machado (2017), realizaram uma reflexão sobre as práticas empregadas e as possibilidades das ferramentas tecnológicas no ensino da biologia, e enfatizam a necessidade de o professor buscar capacitação constante para melhor o resultado de seu exercício profissional e de seu papel social como professor. Além do contexto de ensino aprendizagem voltados a matéria lecionada, o professor contemporâneo, deve ter em mente que ele passa a ser também um educador tecnológico, ou seja, responsável por ensinar o aluno o uso da tecnologia de forma construtivista, indicando as melhores opções de uso para construção do pensamento crítico e melhor absorção de conteúdos que possam servir no seu processo formativo, e, portanto, interferindo no comportamento digital (ROCHA, 2013).

A virtualização dos sistemas educativos pressupõe a alteração dos modelos de ensino e práticas docentes vigentes, e, dessa forma, a situação "obriga" o professor a assumir novos papeis, comunicando-se, portanto, através de formas com as quais não estava habituado (CARRARI; SOUZA; BEHR, 2017). O professor não é responsável apenas pela transmissão de conhecimentos aos seus alunos, pois, nesse momento, deve guiar o processo de aprendizagem do estudante, de forma

RC: 96069

Disponível em: https://www.nucleodoconhecimento.com.br/educacao/ciencias- 
que este consiga desenvolver as suas capacidades, isto é, deve ser auxiliado a aprender a aprender e, desse modo, desenvolver a sua autonomia (ROSALIN; CRUZ; MATTOS, 2017). O professor deve acompanhar, motivar, dialogar, ser líder, mediador, fomentando e mediando uma interação humana positiva (GOULÃO, 2012). É esperado que seja moderador nas relações inter e intrapessoais e que autoavalie o seu desempenho de forma contínua, revendo práticas.

A introdução das tecnologias no ambiente docente é uma forma de estimular os discentes, orientando as suas emoções, afetos e atitudes (DIAS, 2008). O professor, nesse novo cenário tecnológico, deve assumir funções que despertem a criação e uso de recursos digitais, o que implica rever suas estratégias de ensino, dinamizando as interações por meio da tecnologia. Para que seja esse dinamizador, é necessário compreender as especificidades dos canais que possibilitam a comunicação online síncrona e assíncrona (SALMON, 2000). Demanda-se uma boa estrutura de comunicação para que se gere uma autêntica comunidade virtual de aprendizagem, de modo que o aluno esteja conectado e motivado. A comunicação regular com os estudantes, deve ser realizada a partir de diferentes canais de comunicação, para que estes reconheçam que a presença do professor é essencial. A sala de aula virtual "vazia" deve ser ressignificada (GOULÃO, 2012).

A sala de aula sem vida, sem presença social e cognitiva, é um espaço "sem vida" (MOREIRA; FERREIRA; ALMEIDA, 2013). As salas de aula virtuais de comunicação assíncrona são conhecidas como "fóruns". Elas são fundamentais e respondem à essência da educação digital em rede, uma vez que não requerem uma confluência do professor e dos estudantes no espaço e no tempo, e, assim, há uma maior flexibilidade neste modelo educativo (MOREIRA; HENRIQUES; BARROS, 2020). Para que essas salas de aula correspondam a uma poderosa ferramenta de comunicação, é crucial que estejam bem-organizadas e estruturadas, o que necessita que a comunidade conheça as suas regras operacionais e as siga, para

RC: 96069

Disponível em: https://www.nucleodoconhecimento.com.br/educacao/ciencias- 
que o virtual-digital promova uma aprendizagem significativa (SOUZA; ARAGON, 2018). Recomenda-se que haja neste ambiente virtual espaços para cada atividade.

Um espaço para a comunicação de notícias e avisos, outro para que dúvidas dos estudantes sejam sanadas, um outro espaço informal que permita a interação entre alunos e professor de forma mais descontraída e espaços criados para cada tipo de atividade, são estratégias necessárias para que o digital seja eficiente (MOREIRA; HENRIQUES; BARROS, 2020). Há uma série de vantagens promovidas pelas tecnologias digitais, porém, a formação permanente, isto é, continuada, é crucial, uma vez que, nessa área, a inovação e incorporação de novas técnicas acontece o tempo todo, o que demanda mudanças significativas na prática docente (MOREIRA; HENRIQUES; BARROS, 2020). Nesse sentido, é preciso conhecer os softwares, perceber o que se pretende com o seu uso, do ponto de vista pedagógico, e perceber se esse recurso digital específico é o mais adequado (CARRARI; SOUZA; BEHR, 2017).

Isso acontece porque o simples uso de interfaces digitais não garante, por si só, avanços ou inovações nas práticas educativas (SOUZA; ARAGON, 2018). Diversas interfaces da Web Social são subutilizadas quando os referenciais adotados ainda replicam aquelas práticas adquiridas na Web 1.0. Por esses motivos, e, além disso, entendendo a educação digital em rede como um processo que se caracteriza pela utilização de tecnologias digitais de Web Social, torna-se necessária a promoção de práticas pedagógicas e didáticas ativas e construtivas (ROSALIN; CRUZ; MATTOS, 2017). O conhecimento e a aprendizagem devem ser desenvolvidos de forma colaborativa. A educação em rede, em razão de sua própria essência, é um processo que requer o envolvimento profundo de diferentes atores envolvidos nessa articulação, especialmente definição dos objetivos e percursos de aprendizagem da comunidade.

O processo repercute, também, nas relações de proximidade construídas, de forma colaborativa, entre os pares que sustentam os processos de inovação e criação do

RC: 96069

Disponível em: https://www.nucleodoconhecimento.com.br/educacao/ciencias- 
conhecimento a partir de vias digitais (MOREIRA; HENRIQUES; BARROS, 2020). Para que haja a construção coletiva deste novo conhecimento, tem sido cada vez mais comum e rápido o crescimento e ampliação do uso dos Recursos Educacionais Abertos (REA). Esses têm promovido o acesso e uso livre de conteúdos e tecnologias (GOULÃO, 2012). Tais recursos correspondem a uma fonte inesgotável de recursos digitais que podem se vincular às atividades voltadas à apresentação e enriquecimento dos conteúdos. Há plataformas que permitem diferentes formas de abordagem do conhecimento (plataformas que integram vídeo, áudio e imagem, como YouTube, e outras redes/mídias sociais e digitais) (SOUZA; ARAGON, 2018).

\section{SABERES NECESSÁRIOS PARA O ENSINO ONLINE}

Não é privilégio das ciências biológicas se deparar com desafios no processo de ensino aprendizagem, ou mais ainda, do que ensinar e como ensinar. No contexto do ensino online, esses desafios apenas se mostraram mais ampliados ao exigir do professor habilidades tecnológicas pouco desenvolvidas. Duré et al. (2018) ressaltam que o maior desafio dos professores tanto no ensino presencial, quanto no ensino online, é fazer com que os alunos se interessem pelas aulas, por isso, ao buscar sempre abordagens considerando suas necessidades pessoais e sociais, o processo de ensino tende a ser mais efetivo. Outra estratégia que deve ser adotada pelos professores neste processo é a ampla diversificação de mecanismos de ensino, como por exemplo, vídeos no YouTube, filmes, jogos, quis (OLIVETTI e PEIOTTO, 2014; NICOLA e PANIZ, 2017; ARAÚJO et al., 2011; LEITE et al., 2017; LEÃO et al., 2018)

Quadro 1- Saberes docentes e indicações para o ensino online

\begin{tabular}{l|l}
\hline Saberes necessários para o Ensino da Biologia Online & Autores \\
\hline $\begin{array}{l}\text { Adequar as aulas de acordo com a realidade do aluno, } \\
\text { seja social, seja pessoal }\end{array}$ & Leite et al. 2011;
\end{tabular}

RC: 96069

Disponível em: https://www.nucleodoconhecimento.com.br/educacao/ciencias- 


\begin{tabular}{|c|c|}
\hline & $\begin{array}{l}\text { Machado, 2017; Leão } \\
\text { et al., } 2018 .\end{array}$ \\
\hline $\begin{array}{l}\text { Buscar vídeos, jogos, aplicativos que possam trazer } \\
\text { dinamismo ao ensino de biologia }\end{array}$ & $\begin{array}{l}\text { Araújo et al., 2011; } \\
\text { Leão et al., } 2018 .\end{array}$ \\
\hline $\begin{array}{l}\text { Buscar métodos de avaliação que envolvam o aluno, } \\
\text { inclusive com metodologia em grupo, como criação } \\
\text { de vídeos expositivos }\end{array}$ & $\begin{array}{l}\text { Araújo et al., 2011; } \\
\text { Leite et al., 2017; } \\
\text { Leão et al., } 2018 .\end{array}$ \\
\hline Mapa conceitual & Leão et al., 2018 \\
\hline Uso de quiz (Instagram) & Souza et al., 2020 \\
\hline $\begin{array}{l}\text { Pesquisas em diferentes meios de comunicação } \\
\text { online sobre os assuntos expostos. Aproveitando } \\
\text { para desenvolver nesse momento pensamento crítico } \\
\text { e análise de alguns posicionamentos }\end{array}$ & $\begin{array}{l}\text { Machado, } 2017 ; \\
\text { Brandim e Nogueira, } \\
2018\end{array}$ \\
\hline $\begin{array}{l}\text { Diversificação de recursos Youtube, filmes, Jogos, } \\
\text { textos }\end{array}$ & $\begin{array}{l}\text { Olivetti e Peiotto, } \\
\text { 2014; Nicola e Paniz, } \\
2017 .\end{array}$ \\
\hline Adaptação de Linguagem, luzes e & Soares Filho, 2013. \\
\hline
\end{tabular}

Fonte: Autora

Souza et al. (2020) realizaram uma experiência do ensino através da ferramenta de "quiz" no Instagram, como uma espécie de testagem de conhecimentos. Os resultados demonstraram que os alunos se sentiram motivados e empolgados, inclusive desenvolvendo um movimento de competitividade entre si. Avaliando como os alunos se sentiram frente a essa ferramenta, o resultado também foi positivo, pois os alunos se mostraram envolvidos e motivados. Por fim, o cuidado do professor ao lecionar de forma online, buscando atualizar sua linguagem dentro do contexto dos alunos, e averiguando seus recursos tecnológicos como luz e som, certamente farse-á como estratégia no sucesso do ensino através de melhor adesão por parte do aluno (SOARES FILHO, 2013).

RC: 96069

Disponível em: https://www.nucleodoconhecimento.com.br/educacao/ciencias- 
A Base Nacional Comum Curricular (BNCC) aponta a necessidade de um esforço conjunto entre professores, pesquisadores e organizações nacionais para que competências essenciais para os discentes brasileiros da educação básica sejam desenvolvidas, incluindo-se as ligadas ao meio digital (FERREIRA et al., 2021). Essas devem ser desenvolvidas para que as demandas cotidianas sejam atendidas. A BNCC apresenta dez competências que visam uma formação humana e integral, incluindo a "cultura digital". Desse modo, preocupa-se com o desenvolvimento de competências e habilidades relacionadas ao uso das tecnologias digitais em sala de aula, sendo que essas, devem ser adequadas às diversas práticas sociais (MATTAR et al., 2020). Assim, é preciso que a formação continuada auxilie o professor a compreender, utilizar e criar tecnologias da informação e comunicação (CHIOSSI; COSTA, 2018).

O uso de tecnologias digitais deve ser feito de forma crítica, significativa, reflexiva e ética, introduzindo as práticas cotidianas no contexto educacional. O objetivo é promover a comunicação, o acesso, a disseminação de informações, a produção de conhecimentos, a resolução de problemas, o exercício do protagonismo e autoria no processo de interação com tais tecnologias no contexto educacional (LEITE; SILVA, 2017). Nesse sentido, ao compreender a incorporação das tecnologias digitais na construção do processo ensino-aprendizagem e na resolução de problemas cotidianos, a BNCC, sugere que os profissionais devem ser capacitados para que consigam introduzir o digital nas salas de aula (PIFFERO et al., 2020). Os professores de diferentes níveis de ensino e das múltiplas disciplinas devem desenvolver competências e habilidades que permitam esta inclusão (CHIOSSI; COSTA, 2018).

Dessa forma, os programas e políticas nacionais que envolvem a incorporação das tecnologias na educação devem promover estratégias que viabilizem o efetivo acesso ao digital, porém, ainda há inúmeras barreiras e desafios (LEITE; SILVA, 2017). As tecnologias da informação e comunicação devem ultrapassar o uso

RC: 96069

Disponível em: https://www.nucleodoconhecimento.com.br/educacao/ciencias- 
tecnicista e instrumental do digital (PIFFERO et al., 2020). Há dois fatores que podem retardar a acessibilização do digital em sala de aula: as condições físicas e estruturais e a formação inadequada (FERREIRA et al., 2021). Em relação à estruturação das escolas e da própria formação docente, pode-se destacar o Programa Nacional de Tecnologia Educacional (PROINFO), criado ainda em 1997. Este suscitou novos desdobramentos, chegando-se ao Programa de Inovação e Educação Conectada. Tais iniciativas somam-se a outras desenvolvidas desde a década de 1970.

O objetivo é o de disponibilizar uma estrutura computacional às escolas para que, dessa forma, seja possível promover uma qualificação docente adequada, tornando viável o uso da TDIC no contexto da educação (FERREIRA et al., 2021). Com o intuito de estabelecer uma política concreta na área da informática com o intuito de alavancar a economia do país, as tecnologias passaram a integrar os mais diversos contextos, contudo, elas ainda não foram introduzidas de modo eficiente, uma vez que ainda é dificultosa a implementação de uma cultura digital em sala de aula (CHIOSSI; COSTA, 2018). Todavia, com a necessidade da introdução do ensino remoto, algumas desigualdades foram evidenciadas em virtude da pandemia (SARAIVA; TRAVERSINI; LOCKMANN, 2020). Por mais que algumas escolas consigam promover momentos de encontro digital a partir das diferentes plataformas, o acesso ainda é um problema.

Além disso, a falta de domínio quanto ao uso das plataformas, redes e mídias digitais por parte do professor também dificulta a incorporação da tecnologia no ambiente docente. O domínio de certas ferramentas e tecnologias implica o conhecimento sobre tais possibilidades. Novas tecnologias surgem e são aprimoradas a cada dia, o que demanda do professor uma busca constante pelo aperfeiçoamento de suas competências e habilidades relacionadas ao manuseio de tais plataformas e ferramentas digitais (MATTAR et al., 2020). Os saberes necessários ao exercício docente perpassam por alguns campos. Eles são

RC: 96069

Disponível em: https://www.nucleodoconhecimento.com.br/educacao/ciencias- 
classificados a partir de algumas categorias específicas (TARDIF, 2010). Eles são os saberes de ordem disciplinar; os saberes profissionais; os saberes curriculares e os saberes associados ao campo experimental (MATTAR et al., 2020).

As competências tecnológicas que serão cobradas do professor no exercício docente estão ligadas a certos saberes e habilidades relacionados ao manuseio de redes e mídias digitais (FERREIRA et al., 2021). Nesse sentido, a fim de que o aprendizado seja significativo e atrelado ao uso da tecnologia, algumas habilidades tornam-se primordiais, contudo, para que elas possam ser executadas, é preciso que o docente tenha o conhecimento necessário sobre as suas possibilidades de uso (PIFFERO et al., 2020). O domínio de habilidades informáticas, de softwares, de ferramentas, de mídias e dos ambientes virtuais diversos (como Google Meet e outras plataformas) demandam um certo letramento e fluência em linguagem digital (CHIOSSI; COSTA, 2018). Os cursos de formação devem partir dessa ênfase para que o ensino no ambiente virtual promova uma aprendizagem eficiente, dinâmica e atrativa para os alunos.

\section{CONSIDERAÇÕES FINAIS}

Partindo do pressuposto de trazer alguns indicativos para os saberes do professor com relação ao ensino online, este estudo pautou-se na metodologia exploratória, buscando alusões e indicações dentro de outros estudos já realizados. Assim, para elucidar as considerações finais deste estudo resgatou-se a pergunta norteadora: Como os professores de ciências biológicas podem se preparar e quais as ferramentas básicas que devem conhecer para preparar suas aulas online? O estudo demonstrou que os professores do ensino médio e fundamental possuem a necessidade de utilizar de múltiplas ferramentas e estratégias para preparar suas aulas online. Não basta apenas realizar aulas expositivas, é necessário envolver os alunos. A interação com tais tecnologias devem ser estimuladas, porém, para que a

RC: 96069

Disponível em: https://www.nucleodoconhecimento.com.br/educacao/ciencias- 
aprendizagem seja significativa, é necessário o domínio e conhecimento de certas técnicas, plataformas, ferramentas etc.

Algumas ferramentas eficazes apontadas pela literatura são: Mapas conceituais, vídeos do YouTube, filmes, jogos, pesquisa no google e outras redes, enfim, ferramentas que desenvolvam no aluno, não só no contexto da biologia, mas também, que incentive o uso consciente e efetivo das tecnologias. Além disso, alguns cuidados técnicos são fundamentais como: adequação da linguagem à turma, considerando sua faixa etária, luz e áudio. Devido ao cenário pandêmico, e, consequentemente, inexistência de aulas presenciais e possibilidades de ir a campo, este estudo trouxe algumas limitações, que poderiam ser melhor exploradas através de pesquisa com docentes e alunos. Indica-se que estudos posteriores possam ser realizados de forma aplicada com alunos e professores, investigando estratégias e ferramentas que se mostrem efetivas para o ensino da biologia online no ensino médio e fundamental.

\section{REFERÊNCIAS}

ARAÚJO, Magnólia Fernandes; SOUSA, Rute Alves; SOUSA, Ivanise Cortez de. Instrumentalização para o Ensino da Biologia. 2 ed. EDFRN, 2011.

BRANDIM, Maria Rejane Lima; NOGUEIRA, Johnson Fernandes. Ensino de Ciências e de Biologia: reflexões e práticas- Parnaíba: Edufpi, 2018.

CARRARO, W. B. W. H.; SOUZA, M.; BEHR, A. Ferramentas de educação a distância utilizadas por profissionais de contabilidade visando a educação continuada. Revista EDaPECI, v. 17, n. 2, p. 144-160, 2017.

CHIOSSI, R. R.; COSTA, C. S. Novas formas de aprender e ensinar: a integração das tecnologias de informação e comunicação (TIC) na formação de professores da

RC: 96069

Disponível em: https://www.nucleodoconhecimento.com.br/educacao/ciencias- 
educação básica. Texto Livre: Linguagem e Tecnologia, v. 11, n. 2, p. 160-176, 2018.

DIAS, P. Da e-moderação à mediação colaborativa nas comunidades de aprendizagem. Educação, Formação e Tecnologias, v. 1, n. 1, p. 4-10, 2008.

DURÉ, Ravi Cajú; et. al; Ensino De Biologia E Contextualização Do Conteúdo: Quais Temas O Aluno De Ensino Médio Relaciona Com O Seu Cotidiano? Experiências em Ensino de Ciências V.13, No.1, 2018.

FALSARELLA, A. M. Formação continuada e prática de sala de aula: os efeitos da formação continuada na atuação do professor. Campinas, São Paulo: Autores Associados, 2004.

FERREIRA, L. P. S. et al. Autopercepção das competências digitais pelos professores da educação básica sergipana durante o ensino remoto. Scientia Plena Jovem, v. 8, n. 1, 2021.

FERREIRA, T. B.; ALBUQUERQUE, E. B. C.; LEAL, T. F. Formação Continuada de Professores: questões para reflexão. Belo Horizonte: Autêntica, 2007.

GADOTTI, M. Boniteza de um sonho: Ensinar e Aprender com sentido. São Paulo: Editora e Livraria Instituto Paulo Freire, 2008.

GHEDIN, E. Professor Reflexivo: da alienação da técnica à autonomia da crítica. In: PIMENTA, S. G.; GHEDIN, E (Orgs.). Professor reflexivo no Brasil: gênese e crítica de um conceito. $7^{a}$ ed. São Paulo: Cortez, 2012.

GIL, Antonio Carlos Gil. Método de Pesquisa. Ed. Atlas, São Paulo, 2018.

GONÇALVES, Janaína Oliveira. MIRANDA, Maurício Fernando Oliveira de. GONÇALVES JÚNIOR, Edson. Uma reflexão sobre a parceria da família e escola

RC: 96069

Disponível em: https://www.nucleodoconhecimento.com.br/educacao/ciencias- 
em tempos de COVID-19: Aspectos pedagógicos, econômicos e jurídicos. Revista Científica Multidisciplinar Núcleo do Conhecimento. Ano 05, Ed. 11, Vol. 06, pp. 141 154. Novembro de 2020. ISSN: 2448-0959, Link de acesso: https://www.nucleodoconhecimento.com.br/educacao/economicos-e-juridicos, DOI: 10.32749/nucleodoconhecimento.com.br/educacao/economicos-e-juridicos

GOULÃO, M. F. The use of Forums and collaborative learning: A study case. Procedia - Social and Behavioral Sciences, n. 46, p. 672-677, 2012.

JUNGES, F. C.; KETZER, C. M.; OLIVEIRA, V. M. A. de. Formação continuada de professores: saberes ressignificados e práticas docentes transformadas. Educação \& Formação, v. 3, n. 9, p. 88-101, 2018.

LEÃO, Marcelo Franco; et al; Estratégias didáticas voltadas ao ensino das Ciências. Ed. Edibrás. Uberlândia, 2018.

LEITE, M. S.; SILVA, S. R. F. da. Redimensionamento da Computação em Processo de Ensino na Educação Básica: O pensamento Computacional, o Universo e a Cultura Digital. In: VI Congresso Brasileiro de Informática na Educação, 2017.

LEITE, Paula Rayanny Mendonça; et al; O ensino da biologia como uma ferramenta social, crítica e educacional. RECH- Revista Ensino de Ciências e Humanidades Cidadania, Diversidade e Bem-estar. ISSN 2594-8806 - 400. Ano 1, Vol 1, Número 1, Jul-Dez, 2017, p. 400-413

LENZI, Juliana Fernandes de Almeida Castro. SANTOS, Marijara Barbosa Bragato. Sociedade Pós-Moderna Frente À Covid-19: Educadores Em Ação. Revista Científica Multidisciplinar Núcleo do Conhecimento. Ano 06, Ed. 03, Vol. 11, pp. 100 111. Março de 2021. ISSN: 2448-0959, Link de acesso: https://www.nucleodoconhecimento.com.br/educacao/educadores-em-acao

RC: 96069

Disponível em: https://www.nucleodoconhecimento.com.br/educacao/ciencias- 
MACHADO, Claudia Pinto/ Ensino de ciências [recurso eletrônico]: práticas e exercícios para a sala de aula- Caxias do Sul, RS: Educs, 2017.

MATTAR, J. et al. Competências e funções dos tutores online em educação a distância. Educação em Revista, v. 36, 2020.

MOREIRA, J. A.; FERREIRA, A. G.; ALMEIDA, A. C. Comparing communities of inquiry in higher education students: one for all or one for each? OpenPraxis. Internacional Council for Open and Distance Education, v. 5, n. 2, p. 165-178, 2013.

MOREIRA, J. A.; HENRIQUES, S.; BARROS, D. M. V. Transitando de um ensino remoto emergencial para uma educação digital em rede, em tempos de pandemia. Dialogia, n. 34, p. 351-364, 2020.

NICOLA, Jéssica Anese; PANIZ, Catiane Mazocco. A importância da utilização de diferentes recursos didáticos no ensino de biologia. Infor, Inov. Form., Rev. NEaDUnesp, São Paulo, v. 2, n. 1, p.355-381, 2016. ISSN 2525-3476.

OLIVETTI, Maria Madalena de Carvalho; PERIOTTO, Fernando. biologia e as novas tecnologias educacionais, um foco para a educação contemporânea. Revista Eletrônica Científica Inovação e Tecnologia Universidade Tecnológica Federal do Paraná Câmpus Medianeira. Vol.1, p. 9- 2014.

PIFFERO, E. de. L. F. et al. Metodologias Ativas e o ensino de Biologia: desafios e possibilidades no novo Ensino Médio. Ensino \& Pesquisa, v. 18, n. 2, p. 48-63, 2020.

ROCHA, Jéssica. A percepção da ciência pelos alunos do curso de pedagogia UAB/UFMG. V Seminário Internacional de Educação a Distância. UFMG, 2013.

RC: 96069

Disponível em: https://www.nucleodoconhecimento.com.br/educacao/ciencias- 
RODRIGUES, P. M. L.; LIMA, W. dos. S. R.; VIANA, M. A. P. A importância da formação continuada de professores da educação básica: a arte de ensinar e o fazer cotidiano. Saberes Docentes em Ação, v. 3, n. 1, p. 28-47, 2017.

ROSALIN, B. C. M.; CRUZ, J. A. S.; MATTOS, M. B. G. de. A importância do material didático no ensino a distância. Revista on line de Política e Gestão Educacional, v. 21, n. 1, p. 814-830, 2017.

SALMON, G. E-Moderating. The Key to Teaching and Learning Online. London: Kogan Page, 2000.

SARAIVA, K.; TRAVERSINI, C. S.; LOCKMANN, K. A educação emtempos de COVID-19: ensino remoto e exaustão docente. Práxis educativa, v. 15, p. 1-24, 2020.

SOARES FILHO, Daniel. Conteúdos EAD: Pequenos detalhes que fazem a diferença. V Seminário Internacional de Educação a Distância. UFMG, 2013.

SOUZA, Dominique Guimarães; et. al. Redes sociais e o ensino de biologia: $O$ uso do Quis do Instagram como Recurso Didático. Recite - Revista Carioca de Ciência Tecnologia e Educação · December 2020.

SOUZA, S. S. dos. S. de.; ARAGON, G. T. Estilos de aprendizagem e ensino a distância na perspectiva da inclusão. EaD em Foco, v. 8, n. 1, 2018.

TARDIF, M. Saberes docentes e formação profissional. $17^{a}$ ed. Petrópolis, RJ: Vozes, 2010.

TREBIEN, M. M et al. Formação continuada de professores: uma epistemologia da prática. Ambiente: Gestão e Desenvolvimento, v. 13, n. 1, p. 91-102, 2020.

Enviado: Setembro, 2021.

RC: 96069

Disponível em: https://www.nucleodoconhecimento.com.br/educacao/ciencias- 
Aprovado: Setembro, 2021.

RC: 96069

Disponível em: https://www.nucleodoconhecimento.com.br/educacao/ciencias$\underline{\text { biologicas }}$ 